\title{
Observation and Origin of Extraordinary Atomic Mobility at Metal-Semiconductor Interfaces at Low Temperatures
}

\author{
Zumin Wang, ${ }^{1, *}$ Lars P. H. Jeurgens, ${ }^{2}$ Wilfried Sigle, ${ }^{1}$ and Eric J. Mittemeijerer, \\ ${ }^{1}$ Max Planck Institute for Intelligent Systems, Heisenbergstrasse 3, 70569 Stuttgart, Germany \\ ${ }^{2}$ Empa, Swiss Federal Laboratories for Materials Science and Technology, Laboratory for Joining Technologies and Corrosion, \\ Ueberlandstrasse 129, 8600 Duebendorf, Switzerland \\ ${ }^{3}$ Institute for Materials Science, University of Stuttgart, Heisenbergstrasse 3, 70569 Stuttgart, Germany
}

(Received 15 October 2014; revised manuscript received 6 May 2015; published 2 July 2015)

\begin{abstract}
Extraordinarily high mobility of $\mathrm{Si}$ and $\mathrm{Ge}$ atoms at semiconductor ( $\mathrm{Si}, \mathrm{Ge}$ )-metal (Al) interfaces is observed at temperatures as low as $80 \mathrm{~K}$ during thin metal film deposition. In situ $\mathrm{x}$-ray photoemission spectroscopic valence-band measurements reveal a changed chemical bonding nature of the semiconductor atoms, from localized covalentlike to delocalized metalliclike, at the interface with the Al metal. The resulting delocalized bonding nature of the interfacial semiconductor atoms brings about the observed extreme enhancement of their mobility. The finding opens avenues for tailoring reaction kinetics and phase transformations in nanostructured materials, as functional thin-film systems, at ultralow temperatures by dedicated interfacial design.
\end{abstract}

DOI: 10.1103/PhysRevLett.115.016102

PACS numbers: 68.35.Fx, 79.60.-i, 81.15.-z

Atomic mobility in solid materials controls the occurrence and rate of many important material processes, such as (inter)diffusion, chemical reactions, phase transformations, crystal nucleation and growth, as well as recovery and recrystallization [1,2]. In general, energy barriers exist for the movement of atoms in a solid and, consequently, the movement of atoms in a solid is usually thermally activated. Accordingly, atomic mobility is strongly dependent on the temperature, in addition to the structure and the bonding nature (covalent, metallic, or ionic) of the material [3]. The atomic mobility can be enhanced at the surface and interface of materials, due to specific structural, chemical and/or electronic modifications at these locations [4-8]. Evidently, a fundamental understanding and (local) command of atomic mobility are crucial for tailoring the reactivity and long-term stability of materials and their assemblies during processing and service.

In this work, extreme enhancement of the mobility of $\mathrm{Si}$ and $\mathrm{Ge}$ atoms at amorphous semiconductor- ( $\mathrm{Si}, \mathrm{Ge}$ )-metal (Al) interfaces was detected at temperatures as low as $80 \mathrm{~K}$. A 1-nm amorphous $\mathrm{Ge}(a-\mathrm{Ge})$ layer was observed to be "floating" continuously on top of an epitaxially growing $\mathrm{Al}$ layer at $80 \mathrm{~K}$, indicating pronounced atomic mobility of Ge atoms at the $\mathrm{Ge} / \mathrm{Al}$ interface at such an ultralow temperature (i.e., at $T=0.066 T_{m}^{\mathrm{Ge}}$, where $T_{m}$ is the melting point). Similar behavior was observed for a 1-nm amorphous $\mathrm{Si}$ (a-Si) layer on top of $\mathrm{Al}$ at $80 \mathrm{~K}$. In situ X-ray photoemission spectroscopy (XPS) valence-band measurements unambiguously demonstrated the occurrence of the modified chemical bonding nature of the semiconductor atoms at the interface with $\mathrm{Al}$, which provides the basis for the observed extreme enhancement of the atomic mobility at the semiconductor-metal interfaces. Such high atomic mobility at ultralow temperatures $\left(T<0.1 T_{m}\right)$, occurring exclusively at interfaces, may be exploited to enable and/or enhance the phase-transformation and reaction kinetics in nanostructured materials and thin-film systems at low temperatures, as, for example, desired in the manufacturing and low-temperature processing of heat-sensitive materials and their assemblies for various state-of-the-art technologies [9-13].

The experiments were carried out in an ultrahighvacuum (UHV) system $\left(<2 \times 10^{-10} \mathrm{mbar}\right)$. A 50-nm single-crystalline $\mathrm{Al}(111)$ film with an atomically flat surface was prepared on a $\mathrm{Si}(111)$ substrate by thermal evaporation deposition followed by postdeposition annealing at $300{ }^{\circ} \mathrm{C}$ for $1 \mathrm{~h}$ in UHV. The specimen was then cooled to $80 \mathrm{~K}$ in UHV on a cooling stage with liquidnitrogen flow. Next a 1-nm amorphous Si or Ge layer was deposited onto the cooled $\mathrm{Al}(111)$ surface by thermal evaporation. Finally, a 20-nm Al overlayer was deposited by thermal evaporation (deposition rate $10 \mathrm{~nm} / \mathrm{min}$ ), again at $80 \mathrm{~K}$. The thus-prepared specimens, referred to as $\mathrm{Al}_{20-\mathrm{nm}}\left|\mathrm{Si}_{1-\mathrm{nm}}\right| \mathrm{Al}(111)$ and $\mathrm{Al}_{20-\mathrm{nm}}\left|\mathrm{Ge}_{1-\mathrm{nm}}\right| \mathrm{Al}(111)$, respectively, were removed from UHV for subsequent investigation by Auger electron spectroscopy (AES) depth profiling and by cross-sectional TEM. See the Supplemental Material [14] for more experimental details.

The AES composition (elemental)-depth profile of the $\mathrm{Al}_{20-\mathrm{nm}}\left|\mathrm{Si}_{1-\mathrm{nm}}\right| \mathrm{Al}(111)$ specimen is shown in Fig. 1(a). The remaining part (see following) of the original $a$-Si layer is clearly resolved at the depth (of deposition) of about $20 \mathrm{~nm}$ below the surface. However, unexpectedly, a significant amount of $\mathrm{Si}$ is also found at the outer surface of the specimen (i.e., on top of the 20-nm thick $\mathrm{Al}$ top layer). Note that no Si could be detected within the 20-nm Al 


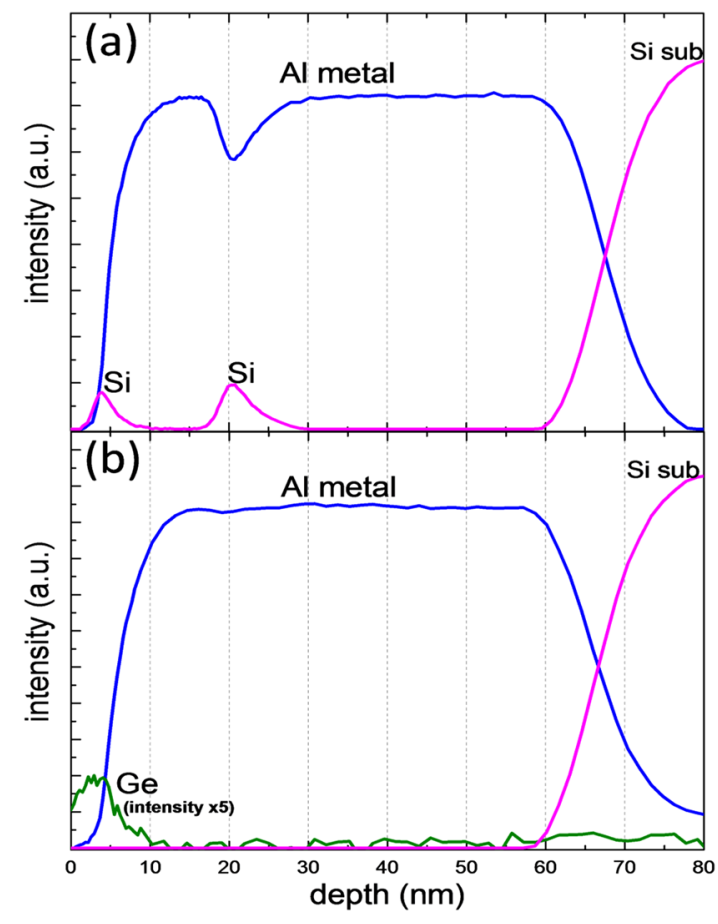

FIG. 1 (color online). AES composition (elemental)depth profiles of the (a) $\mathrm{Al}_{20-\mathrm{nm}}\left|\mathrm{Si}_{1-\mathrm{nm}}\right| \mathrm{Al}(111)$ and (b) $\mathrm{Al}_{20-\mathrm{nm}}\left|\mathrm{Ge}_{1-\mathrm{nm}}\right| \mathrm{Al}(111)$ specimens.

overlayer by AES. The AES composition (elemental)-depth profile of the $\mathrm{Al}_{20-\mathrm{nm}}\left|\mathrm{Ge}_{1-\mathrm{nm}}\right| \mathrm{Al}(111)$ specimen is shown in Fig. 1(b). Very strikingly, no Ge is detected at the depth (of deposition) of about $20 \mathrm{~nm}$ below the surface; instead, the entire 1-nm thick Ge layer has relocated on top of the subsequently deposited $\mathrm{Al}$ layer.

Detailed, atomic-scale analyses of the cross section of the $\mathrm{Al}_{20-\mathrm{nm}}\left|\mathrm{Si}_{1-\mathrm{nm}}\right| \mathrm{Al}(111)$ specimen by energy-dispersive $\mathrm{x}$-ray spectroscopy (EDX) elemental mapping and HRTEM are shown in Fig. 2. An EDX line scan of the Si-K signal from the top surface to the $\mathrm{Al}(111)$ substrate revealed the (exclusive) presence of Si both at its original (sandwiched) location and at the outer surface [Fig. 2(a)], which is fully consistent with the AES analysis [Fig. 1(a)]. Corresponding EDX mappings of the $\mathrm{Si}-\mathrm{K}$ and $\mathrm{Al}-\mathrm{K}$ signals of the specimen are shown in Figs. 2(b) and 2(c), respectively. The Si-K mapping clearly evidences the partitioning of the original 1-nm Si layer into two laterally more-or-less homogenous sublayers present at just below and above the subsequently deposited Al layer [Fig. 2(b)]. The corresponding cross-sectional HRTEM image of the specimen is shown in Fig. 2(d). This HRTEM image demonstrates that the $\mathrm{Al}$ overlayer had grown epitaxially with respect to the $\mathrm{Al}(111)$ substrate [see the fast Fourier transform (FFT) of the HRTEM image in the inset of Fig. 2(d)]. No lattice fringes corresponding to crystalline $\mathrm{Si}$ can be detected in the HRTEM image, indicating an amorphous state of the $\mathrm{Si}$ phase below and above the epitaxially grown Al layer (see above).

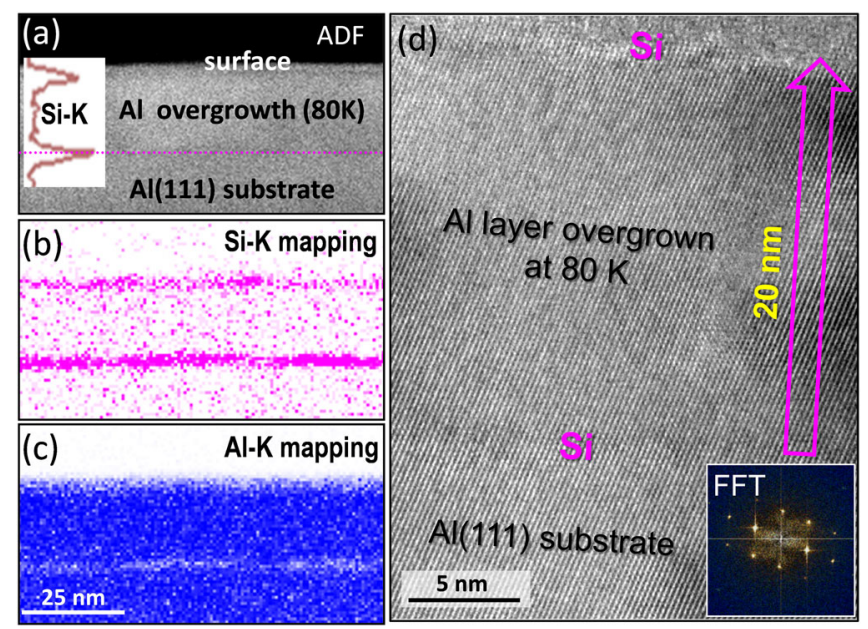

FIG. 2 (color online). Cross-sectional EDX and HRTEM investigation of the $\mathrm{Al}_{20-\mathrm{nm}}\left|\mathrm{Si}_{1-\mathrm{nm}}\right| \mathrm{Al}(111)$ specimen. (a) Annular dark-field (ADF) TEM image. An EDX line scan of the Si-K signal from the top surface to the $\mathrm{Al}(111)$ substrate has been incorporated in the image. (b),(c) EDX mappings of the Si-K and Al-K signals, respectively, of the same location as in (a). (d) Cross-sectional HRTEM image, with its FFT shown in the inset.

Cross-sectional EDX mapping and HRTEM analyses of the $\mathrm{Al}_{20-\mathrm{nm}}\left|\mathrm{Ge}_{1-\mathrm{nm}}\right| \mathrm{Al}(111)$ specimen are shown in Fig. 3. In agreement with the measured AES composition-depth profile [Fig. 1(b)], practically the entire 1-nm Ge layer has relocated at the outer surface (i.e., on top of the subsequently deposited $\mathrm{Al}$ layer). Only a tiny trace of Ge can be detected at the original (sandwiched) location, about $20 \mathrm{~nm}$ below the outer surface: see the EDX line scan of the Ge-K signal in Fig. 3(a) and the EDX mappings of the

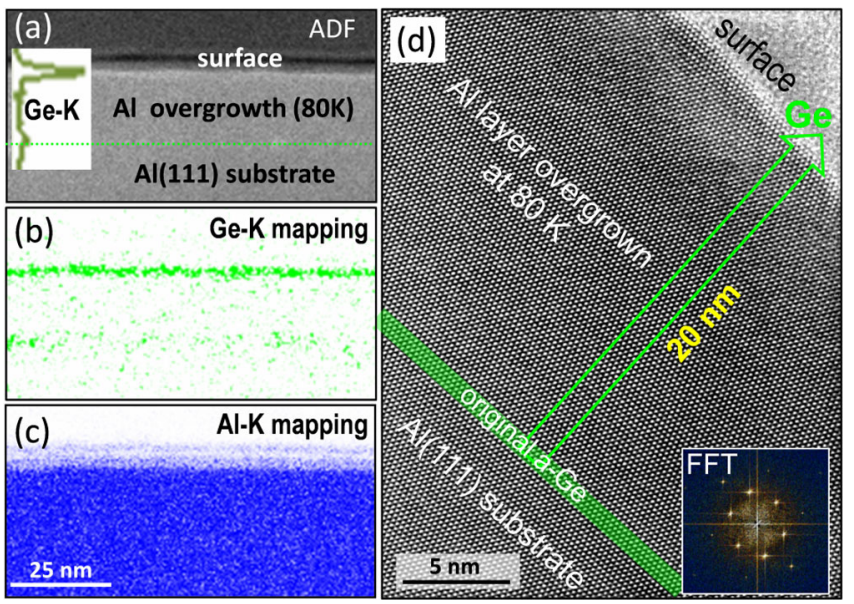

FIG. 3 (color online). Cross-sectional EDX and HRTEM investigation of $\mathrm{Al}_{20-\mathrm{nm}}\left|\mathrm{Ge}_{1-\mathrm{nm}}\right| \mathrm{Al}(111)$ specimen. (a) $\mathrm{ADF}$ TEM image. An EDX line scan of the Ge-K signal from the top surface to the $\mathrm{Al}(111)$ substrate has been incorporated in the image. (b),(c) EDX mappings of the Ge-K and Al-K signals, respectively, of the same location as in (a). (d) Cross-sectional HRTEM image, with its FFT shown in the inset. 
Ge-K and Al-K signals in Figs. 3(b) and 3(c), respectively. The corresponding cross-sectional HRTEM investigation [Fig. 3(d)] revealed the occurrence of an epitaxially grown $\mathrm{Al}$ overlayer without indication of any $(\mathrm{Ge})$ inclusion in the overgrown layer. These observations strongly indicate that the original 1-nm Ge layer has repositioned itself continuously to the top surface during the subsequent $\mathrm{Al}$ deposition step at $80 \mathrm{~K}$. Such a floating Ge film layer appears to be continuous [see Figs. 3(a) and 3(b) and the corresponding high angle annular dark-field-STEM images shown in the Supplemental Material [14]], and no particles of crystalline or amorphous Ge could be indicated.

Therefore, both AES and cross-sectional TEM investigations have evidenced the striking relocalization of the $\mathrm{Si}$ layer in the $\mathrm{Al}_{20-\mathrm{nm}}\left|\mathrm{Si}_{1-\mathrm{nm}}\right| \mathrm{Al}(111)$ specimen, and more pronouncedly, the relocalization of the Ge layer in the $\mathrm{Al}_{20-\mathrm{nm}}\left|\mathrm{Ge}_{1-\mathrm{nm}}\right| \mathrm{Al}(111)$ specimen, during $\mathrm{Al}$ layer deposition even at $80 \mathrm{~K}$. Obviously, in order to realize such continuous relocalization of the $\mathrm{Ge}(\mathrm{Si})$ layer, $\mathrm{Ge}(\mathrm{Si})$ and/ or $\mathrm{Al}$ atoms must be able to diffuse in the thin $\mathrm{Ge}(\mathrm{Si})$ layer during $\mathrm{Al}$ deposition. Considering the similar sizes of $\mathrm{Al}$ and $\mathrm{Ge}(\mathrm{Si})$ atoms [15], the possible diffusion of $\mathrm{Al}$ in the $\mathrm{Ge}(\mathrm{Si})$ layer should be realized by a substitutional-type (rather than an interstitial-type) diffusion mechanism, which requires a high mobility of $\mathrm{Ge}(\mathrm{Si})$ atoms in the layer. Therefore, irrespective of the exact operating diffusant $[\mathrm{Ge}(\mathrm{Si})$ or $\mathrm{Al}$, or both], the above experimental observations indicate compellingly the occurrence of an anomalously high $\mathrm{Ge}(\mathrm{Si})$ atomic mobility in the semiconductor $\mathrm{Ge}(\mathrm{Si})$ layer in contact with the $\mathrm{Al}$ metal at very low temperatures.

The atomic mobilities of $\mathrm{Si}$ and $\mathrm{Ge}$ at low temperatures in bulk Si and bulk Ge are extremely small, owing to the strong covalent bonding of the semiconductor atoms [3] (bond energies of $2.34 \mathrm{eV}$ for $\mathrm{Si}-\mathrm{Si}$ and $1.95 \mathrm{eV}$ for $\mathrm{Ge}-\mathrm{Ge}$ [16]). At room temperature, any (inter)diffusion of Si and $\mathrm{Ge}$ is practically impossible (self-diffusion lengths for $120 \mathrm{~s}$ at RT, extrapolated from diffusion data at high temperatures, are $1.9 \times 10^{-27} \mathrm{~m}$ in Ge bulk [17] and $2.5 \times$ $10^{-41} \mathrm{~m}$ in Si bulk [18]). Against this background, the very high mobility of $\mathrm{Si}$ and $\mathrm{Ge}$ atoms at the $a-\mathrm{Si} / \mathrm{Al}$ and $a$-Ge/ $\mathrm{Al}$ interfaces at $80 \mathrm{~K}\left(T<0.1 T_{\mathrm{m}}\right)$ is very surprising.

To reveal the underlying mechanism for the strikingly high mobility at the semiconductor-metal interface, the electronic structure of interfacial $\mathrm{Ge}$ in contact with $\mathrm{Al}$ metal was investigated through in situ XPS valence-band (VB) measurements. Ultrathin Ge films [19] of different average thicknesses from 100 monolayers (MLs) (1 ML is defined here as the atomic diameter of $\mathrm{Ge}=0.25 \mathrm{~nm}$ [15], corresponding to $1.1 \times 10^{19} \mathrm{Ge}$ atoms per unit film area) down to $1 \mathrm{ML}$ were grown onto a clean $\mathrm{Al}(111)$ surface, which was cooled by liquid nitrogen. VB spectra were directly recorded in situ after deposition of the ultrathin Ge film of each thickness. The VB spectra of the ultrathin Ge films, resolved by subtracting the Al-substrate

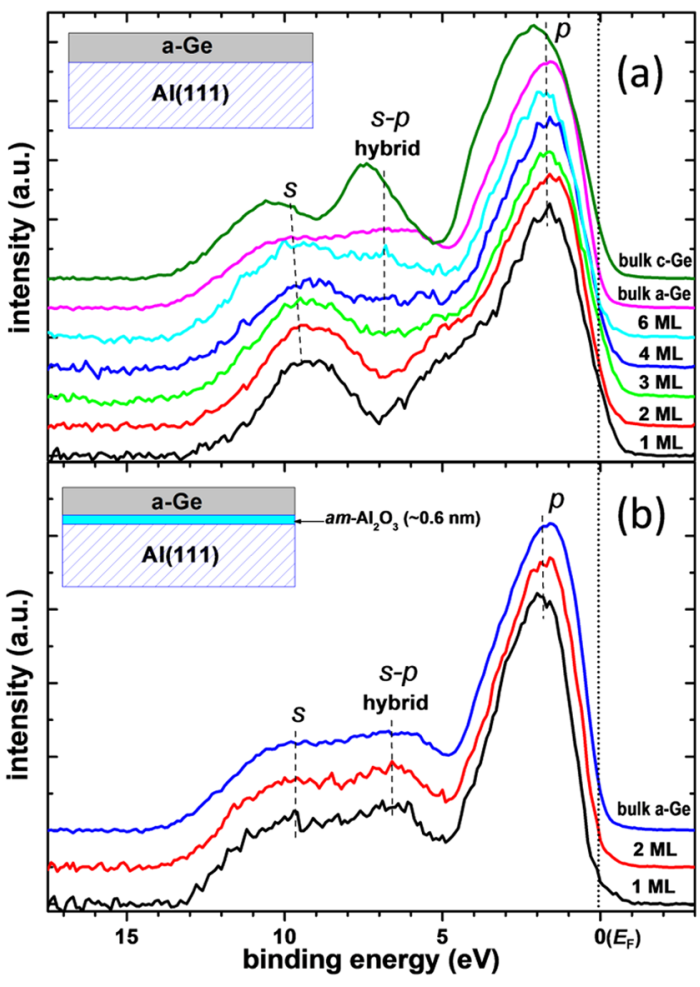

FIG. 4 (color online). (a) Evolution of the valence-band spectra (with $\mathrm{E}_{\mathrm{F}}$ at $0 \mathrm{eV}$ ) of ultrathin $\mathrm{Ge}$ films on $\mathrm{Al}(111)$ with decreasing Ge thickness from in situ XPS measurements. The valence-band spectra of bulk $a$-Ge (100 ML) and bulk single-crystalline Ge $(c-\mathrm{Ge})$ are shown for comparison. All the spectra have been normalized with respect to their maximum height and a constant offset in intensity has been added in order to avoid any overlapping of the spectra. (b) Measured valence-band spectra of 1-ML and 2-ML Ge thin films grown on 0.6-nm amorphous- $\mathrm{Al}_{2} \mathrm{O}_{3} / \mathrm{Al}(111)$.

contribution from the measured spectra [20], are shown in Fig. 4(a) for various film thicknesses.

As follows from Fig. 4(a), for $\mathrm{Ge}$ film thicknesses $\geq 6 \mathrm{ML}$, the VB structure is comparable to that of bulk $a$-Ge (and also to that of small Ge clusters); i.e., a considerable intensity appears in the binding energy range of 6-7 eV, which is characteristic of a strong hybridization $\left(s p^{3}\right)$ of $s$ and $p$ states occurring in the semiconductor Ge (or Si) bulk [21] or small clusters [22-24]. However, with decreasing Ge film thickness $<6 \mathrm{ML}$, the $s$ and $p$ states in the Ge valence-band spectrum become gradually separated, resulting in a gradual disappearance of this $s$ - $p$ hybridization feature; the $s-p$ hybridization feature has practically completely vanished for Ge film thicknesses of $2 \mathrm{ML}$ and less. Such a nearly complete separation of $s$ and $p$ valence states has been predicted theoretically and observed experimentally for liquid Ge [25] in which any covalent bonding of Ge atoms by $s p^{3}$ hybridization has broken down and metallic bonding prevails instead [25-27]. Hence, the XPS VB study suggests that the chemical bonding of the interfacial $\mathrm{Ge}$ atoms in the very vicinity of metallic $\mathrm{Al}$ 
becomes similar to that in liquid Ge, which is metallic. A clearly observable increased number of electronic states at the Fermi level $E_{F}$ for the ultrathin Ge films on $\mathrm{Al}$ (see the VB spectra of ultrathin Ge films in Fig. 4(a), and compare it with that of bulk $a-\mathrm{Ge}$ ) is furthermore indicative of the metallic nature of $a-\mathrm{Ge}$ at the $a-\mathrm{Ge} / \mathrm{Al}$ interface. This change of bonding character from (localized) covalentlike to (nonlocalized) metalliclike, in possible association with a high local density of vacancylike defects at the interface $[8,28,29]$, is thereby the key for the surprisingly high mobility at the interface with $\mathrm{Al}$ even at $80 \mathrm{~K}$. The atomic mobility (diffusivity) of metallized Ge can be estimated on the basis of the extrapolated self-diffusion data [30] in liquid Ge. This estimated diffusion coefficient of metallized Ge is in the range of $10^{-18}-10^{-17} \mathrm{~m}^{2} \mathrm{~s}^{-1}$ at $80 \mathrm{~K}$, which results in a corresponding diffusion length (for $120 \mathrm{~s}$ ) of about $10-30 \mathrm{~nm}$, which is consistent with the observed length scale of mass transport pertaining to the experimental results. Recognizing the structural similarity of $\mathrm{Si}$ and $\mathrm{Ge}$, a similar mechanism should also operate for $\mathrm{Si}$ (and presumably for other covalent semiconductors) in contact with $\mathrm{Al}$, as already suggested by the here-observed very high mobility of $\mathrm{Si}$ at the interface with $\mathrm{Al}$.

As follows from Fig. 4(a), the $s-p$ hybridization feature emerges in the VB spectrum for $a$-Ge film thicknesses $>2 \mathrm{ML}$, implying that the Ge changes its bonding nature only in the very vicinity (i.e., at a distance $\leq 2 \mathrm{ML}$ ) of the $\mathrm{Al}$ metal. To substantiate the above experimental findings and interpretation, in a further experiment the clean $\mathrm{Al}(111)$ surface was first oxidized in situ (in $10^{-6}$ mbar of pure oxygen for $100 \mathrm{~min}$ ) to form an atomically flat, 0.6-nm-thick amorphous- $\mathrm{Al}_{2} \mathrm{O}_{3}$ insulator film at the surface $[31,32]$, on which subsequently $\mathrm{Ge}$ films, with average thicknesses of 1 and $2 \mathrm{ML}$, were deposited under identical conditions as indicated above. The resolved (i.e., after subtraction of the substrate contribution) VB spectra of these 1- and 2-ML Ge films are shown in Fig. 4(b). Evidently, the ultrathin Ge films grown on the (0.6-nm) oxidized $\mathrm{Al}(111)$ substrate show a VB structure, which is practically identical to that of bulk $a$-Ge, which contrasts with the observations for ultrathin Ge films in direct contact with $\mathrm{Al}(111)$. These experiments convincingly show that Ge (and presumably other covalent semiconductors), only when in the very vicinity (distance $\leq 2 \mathrm{ML}$ ) of a metal, can change their covalent bonding nature to metallic nature and thereby gain an extraordinarily high interfacial mobility locally, at the interface with the metal, at low temperatures.

The modification of the electronic structure of a crystalline semiconductor by the presence of a nearby interface with a metal has been investigated by theoretical calculations, recognizing that under such a condition the electrons in the semiconductor would experience an additional image potential from the metal (i.e., a short-range electrostatic interaction occurs for electrons in the semiconductor and their image charges in the metal) [33-36]. These theoretical calculations have predicted that the band gap of the semiconductor can be significantly reduced or even closed in the very vicinity ( $\leq 5 \AA$ [35], $\leq 10 \AA$ [36]) of the metal, as a result of an image potentialinduced local energy-band bending of the semiconductor. Consequently, the interfacial semiconductor may indeed become metallic. The theoretical prediction, together with recent experimental confirmations using ultrathin-film systems (see, e.g., Ref. [37]), agrees very well with the present experimental observations for ultrathin Ge films on the Al metal. However, these theoretical calculations on band-gap modification provide no direct information on the change of the nature of the chemical bonding in the semiconductor close to the interface with the metal. The present experimental XPS investigations have shown that the chemical bonding of amorphous Ge can become similar to that in liquid $\mathrm{Ge}$ and metalliclike close to the interface with a metal. The authors are not aware of any reported theoretical calculations for semiconductor-metal interfaces that predict such a modification of the chemical bonding nature of the semiconductor interface layer.

Deposition of $\mathrm{Al}$ onto the 1-nm thick $a$-Ge layer deposited on the $\mathrm{Al}(111)$ substrate, as performed in the present study, results in a doubling of the metalliclike interfacial $\mathrm{Ge}$ layer thickness (i.e., $2 \times 2 \mathrm{ML} \approx 1 \mathrm{~nm}$ ), since the bonding-modification effect acts at the two opposite Ge/Al interfaces of the sandwiched Ge film. This suggests that practically all Ge atoms constituting the sandwiched 1-nm Ge layer gain an extreme atomic mobility and can all thus reposition themselves at positions such that the system Gibbs energy becomes reduced. There is practically no mutual solubility between Ge and $\mathrm{Al}$ at low temperatures (say, below $500 \mathrm{~K}$ ) [38]. Then, considering the much smaller surface energy of $a$-Ge $\left(\gamma_{\{\mathrm{Ge}\}}=0.7 \mathrm{~J} \mathrm{~m}^{-2}\right.$ at $\left.80 \mathrm{~K} \mathrm{[10])}\right)$ as compared to that of $\operatorname{Al}(111)\left(\gamma_{\langle\mathrm{Al}\rangle}=1.1 \mathrm{~J} \mathrm{~m}^{-2}\right.$ at $\left.80 \mathrm{~K}[10]\right)$, the highly mobile Ge atoms will tend to move towards the top surface and the $\mathrm{Al}$ atoms will tend to diffuse towards the $\mathrm{Al}(111)$ substrate during $\mathrm{Al}$ deposition. As a consequence, the continuously deposited (and continuously with Ge "exchanged") Al can thus grow epitaxially on the $\mathrm{Al}(111)$ substrate (which is for this $\mathrm{Al}$ the thermodynamically most favored configuration), as observed. Such continuous atomic rearrangement in the evolving thin-film or substrate system, as driven by the lowering of the surface energy, is possible only due to the anomalously high mobility of the interfacial Ge atoms at the $a$-Ge/Al interface. Such surface-energy-driven movement can analogously occur for the $\mathrm{Al} / \mathrm{Si} / \mathrm{Al}(111)$ system, but in a possibly less outspoken way, as in this case the driving force is also positive but smaller $\left(\gamma_{\{\mathrm{Si}\}}=1.0 \mathrm{~J} \mathrm{~m}^{-2}<\gamma_{\langle\mathrm{Al}\rangle}=1.1 \mathrm{~J} \mathrm{~m}^{-2} \quad[10,39]\right)$, which explains for this case the observed partitioning (i.e., only partial relocation) of the original 1-nm $a$-Si layer into two layers: one below and one above the overgrown $\mathrm{Al}$ layer. 
Following the above discussion, it can further be predicted that the extraordinary atomic mobility would become less pronounced or even disappear if the Ge or Si layer on the metal becomes sufficiently thick or if it is instead deposited on an insulator surface. Corresponding, additional experiments, as also carried out in the present project, have indeed shown much reduced ( $\mathrm{Si}, \mathrm{Ge}$ ) floating behavior for specimens including a thicker Ge layer or an ultrathin $\mathrm{Al}_{2} \mathrm{O}_{3}$ insulator layer (see the Supplemental Material [14]).

This work provides compelling experimental evidence for the occurrence of extraordinarily high mobility of interfacial $\mathrm{Si}$ and $\mathrm{Ge}$ atoms in contact with $\mathrm{Al}$ metal at temperatures as low as $80 \mathrm{~K}$. A dedicated in situ valenceband XPS study unequivocally revealed a change of the bonding nature of an ultrathin $\mathrm{Ge}$ layer at the $a-\mathrm{Ge} / \mathrm{Al}$ interface from localized covalentlike to delocalized metalliclike, which accounts for the observed extraordinarily high interfacial atomic mobility. These fundamental findings illuminate the possibly anomalous behavior of atoms at interfaces and thus provide avenues for tailoring reaction kinetics and phase transformations in nanostructured materials, as functional thin-film systems, at ultralow temperatures by dedicated interfacial design.

The authors are grateful to Dipl. Ing. P. Schützendübe and Dipl. Ing. B. Siegle for performing the AES measurements, to U. Salzberger for preparation of the TEM specimens, and to Dr. F. Phillipp for performing part of the TEM measurements (all at the Max Planck Institute for Intelligent Systems).

*Corresponding author.

Present address: School of Materials Science \& Engineering, Tianjin University, 300072 Tianjin, China. z.wang@is.mpg.de; z.wang@tju.edu.cn

[1] E. J. Mittemeijer, Fundamentals of Materials Science (Springer, Berlin Heidelberg, 2011).

[2] R. W. Balluffi, S. Allen, and W. C. Carter, Kinetics of Materials (Wiley, Hoboken, 2005).

[3] H. Mehrer, Diffusion in Solids (Springer, Berlin Heidelberg, 2007).

[4] A. P. Sutton and R. W. Balluffi, Interfaces in Crystalline Materials (Oxford University Press, Oxford, 1995).

[5] A. Hiraki, Surf. Sci. Rep. 3, 357 (1983).

[6] T. T. Tsong, Prog. Surf. Sci. 67, 235 (2001).

[7] P. C. Snijders and H. H. Weitering, Rev. Mod. Phys. 82, 307 (2010).

[8] Z. Wang, M. Saito, K. P. McKenna, L. Gu, S. Tsukimoto, A. L. Shluger, and Y. Ikuhara, Nature (London) 479, 380 (2011).

[9] Z. M. Wang, J. Y. Wang, L.P. H. Jeurgens, and E. J. Mittemeijer, Phys. Rev. Lett. 100, 125503 (2008).

[10] Z. M. Wang, J. Y. Wang, L. P. H. Jeurgens, and E. J. Mittemeijer, Phys. Rev. B 77, 045424 (2008).

[11] J. Janczak-Rusch, G. Kaptay, and L. P. H. Jeurgens, J. Mater. Eng. Perform. 23, 1608 (2014).

[12] K. Toko, R. Numata, N. Oya, N. Fukata, N. Usami, and T. Suemasu, Appl. Phys. Lett. 104, 022106 (2014).
[13] A. R. Zanatta and M. E. Kordesch, J. Appl. Phys. 116, 073511 (2014).

[14] See Supplemental Material at http://link.aps.org/ supplemental/10.1103/PhysRevLett.115.016102 for more experimental details and additional experimental results.

[15] J. C. Slater, J. Chem. Phys. 41, 3199 (1964).

[16] CRC Handbook of Chemistry and Physics, edited by W. M. Haynes, 92nd ed. (CRC Press, Boca Raton, 2011).

[17] E. Hüger, U. Tietze, D. Lott, H. Bracht, D. Bougeard, E. E. Haller, and H. Schmidt, Appl. Phys. Lett. 93, 162104 (2008).

[18] H. Bracht, E. E. Haller, K. Eberl, M. Cardona, and R. ClarkPhelps, Mater. Res. Soc. Symp. Proc. 527, 335 (1998).

[19] Ge was chosen (instead of $\mathrm{Si}$ ) for investigation because of its much higher photoionization cross section of valence electrons, which allows a (more) reliable determination of the valence band spectrum even for very thin (e.g.. $1 \mathrm{ML})$ layers.

[20] Except for the $\mathrm{VB}$ measurement of the clean $\mathrm{Al}(111)$ surface, the measured VB spectra constitute contributions from both the infinitely thick $\mathrm{Al}$ substrate and the ultrathin Ge film. To determine the VB spectra of the ultrathin $\mathrm{Ge}$ films of various thicknesses, the contribution from the $\mathrm{Al}$ substrate was subtracted from the measured VB spectra of the Ge-film-Al-substrate system, following the evaluation procedures developed by P. C. Snijders, L. P. H. Jeurgens, and W. G. Sloof in Surf. Sci. 496, 97 (2002).

[21] L. Ley, S. Kowalczyk, R. Pollak, and D. A. Shirley, Phys. Rev. Lett. 29, 1088 (1972).

[22] X. Gong, Phys. Rev. B 52, 14677 (1995).

[23] C. Bostedt, T. van Buuren, T. M. Willey, N. Franco, T. Möller, and L. J. Terminello, J. Electron Spectrosc. Relat. Phenom. 126, 117 (2002).

[24] A. J. Williamson, C. Bostedt, T. van Buuren, T. M. Willey, L. J. Terminello, G. Galli, and L. Pizzagalli, Nano Lett. 4, 1041 (2004).

[25] W. Jank and J. Hafner, Phys. Rev. B 41, 1497 (1990).

[26] R. W. Keyes, Phys. Rev. 84, 367 (1951).

[27] W. Jank and J. Hafner, Europhys. Lett. 7, 623 (1988).

[28] C. Bos, F. Sommer, and E. J. Mittemeijer, Philos. Mag. 87, 2245 (2007).

[29] M. Biglari and E. J. Mittemeijer, Philos. Mag. 94, 801 (2014).

[30] S. M. Chathoth, B. Damaschke, T. Unruh, and K. Samwer, Appl. Phys. Lett. 94, 221906 (2009).

[31] F. Reichel, L. P. H. Jeurgens, G. Richter, P. A. van Aken, and E. J. Mittemeijer, Acta Mater. 55, 6027 (2007).

[32] D. Flötotto, Z. M. Wang, and E. J. Mittemeijer, Surf. Sci. 633, 1 (2015).

[33] J. C. Inkson, J. Phys. C 6, 1350 (1973).

[34] P. W. Anderson, in Elementary Excitations in Solids, Molecules, and Atoms, edited by J. Devreese, A. B. Kunz, and T. C. Collins (Springer New York, 1974), p. 1.

[35] J. P. A. Charlesworth, R. W. Godby, and R. J. Needs, Phys. Rev. Lett. 70, 1685 (1993).

[36] R. Arita, Y. Tanida, K. Kuroki, and H. Aoki, Phys. Rev. B 64, 245112 (2001).

[37] A. Visikovskiy, K. Mitsuhara, M. Hazama, M. Kohyama, and Y. Kido, J. Chem. Phys. 139, 144705 (2013).

[38] T. B. Massalski, Binary Alloy Phase Diagrams, 2nd ed. (ASM International, Materials Park, Ohio, 1990), Vol. 1.

[39] L. P. H. Jeurgens, Z. M. Wang, and E. J. Mittemeijer, Int. J. Mat. Res. 100, 1281 (2009). 